\title{
Fingerprinting of traditionally produced red wines using liquid chromatography combined with drift tube ion mobility-mass spectrometry
}

\author{
Tim J. Causon ${ }^{\mathrm{a}, *}$, Violeta Ivanova-Petropulos ${ }^{\mathrm{b}}$, Dragana Petrusheva ${ }^{\mathrm{b}}$, Elena Bogeva ${ }^{\mathrm{b}}$, \\ Stephan Hann ${ }^{a}$ \\ a Division of Analytical Chemistry, Department of Chemistry, University of Natural Resources and Life Sciences (BOKU), Muthgasse 18, 1190, Vienna, Austria \\ ${ }^{\mathrm{b}}$ Faculty of Agriculture, University "Goce Delcev", Krste Miriskov, 10-A, 2000, Štip, Republic of Macedonia
}

\section{H I G H L I G H T S}

- LC $\times$ IM-TOFMS used for fingerprinting of traditional wines from the Republic of Macedonia.

- Metabolite collision cross sections reported based on consensus values from a standardized and reproducible procedure.

- Fingerprinting approach used to produce lists of statistically characteristic putative metabolites for varieties.

- Up to seven identification points can be generated for a single metabolite across two measurement modes.

\section{A R T I C L E I N F O}

\section{Article history:}

Received 31 July 2018

Received in revised form

23 October 2018

Accepted 20 November 2018

Available online 23 November 2018

\section{Keywords:}

CCS

HPLC

Fingerprinting

Ion mobility-mass spectrometry

Metabolomics

Wine
G R A P H I C A L A B S T R A C T

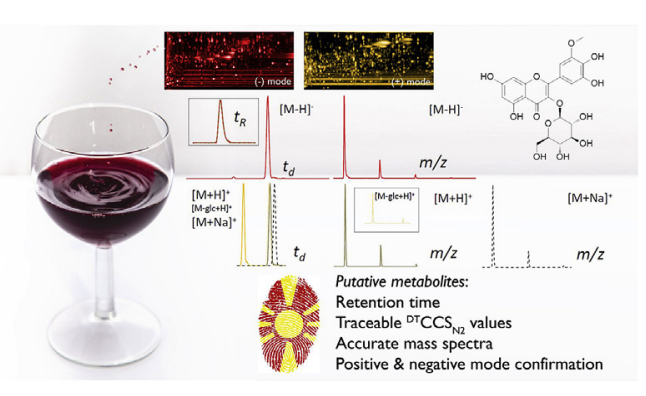

\begin{abstract}
A B S T R A C T
The characterization of wine via MS-based metabolic fingerprinting techniques remains a challenging undertaking due to the large number of phenolic compounds that cannot be confidently annotated and identified within analytical workflows. The combination of high performance liquid chromatography with low-field drift tube ion mobility time-of-flight mass spectrometry (HPLC $\times$ IMS-TOFMS) offers potential for the confident characterization and fingerprinting of wine using a metabolomics-type workflow. In particular, the use of collision cross section values from low-field drift tube IMS using nitrogen as drift gas $\left({ }^{\mathrm{DT}} \mathrm{CCS}_{\mathrm{N} 2}\right)$ in addition to retention time and a high resolution mass spectrum for putative compounds allows rugged statistical assessment and identity confirmation using CCS libraries $(<0.5 \%$ error) to be performed. In the present work, an HPLC $\times$ IMS-TOFMS platform has been utilized for the fingerprinting of 42 traditionally produced red wines emanating from the Republic of Macedonia. After establishing the reliability of ${ }^{\mathrm{DT}} \mathrm{CCS}_{\mathrm{N} 2}$ as an identification point for wine metabolomics in both ionization modes, fingerprinting of wines according to grape variety was undertaken and a full dataset containing retention, accurate mass and ${ }^{\mathrm{DT}} \mathrm{CCS}_{\mathrm{N} 2}$ values used to derive lists of compounds found to be statistically characteristic for each variety. Putative compounds were further assessed by assignment of in-source and post-drift mass fragments aligned according to retention time, drift time, and accurate
\end{abstract}

\footnotetext{
* Corresponding author. Division of Analytical Chemistry, Department of Chemistry, University of Natural Resources and Life Sciences (BOKU Vienna), Austria.

E-mail address: tim.causon@boku.ac.at (T.J. Causon).
} 
mass providing up to seven identification points for a single compound when data from both positive and negative mode measurements are combined.

() 2018 Elsevier B.V. All rights reserved.

\section{Introduction}

The analytical characterization of wine via targeted and nontargeted metabolomics strategies has proven to be valuable for improving understanding of wine chemistry and establishment of reliable varietal and geographic fingerprints [1-3]. The economic reasons for development of analytical workflows dedicated to wine analysis center strongly on goals such as establishment of food provenance, detection of fraud/adulteration, and detailed studies to understand of the roles of attributes such as variety, geographic origin, terrior, vintage and wine making style on the quality of the final product. While targeted analysis is recognized to provide a rugged means to facilitate wine differentiation via relative and absolute quantification strategies, some of the demands of the aforementioned goals render this approach rather limited as the scope of compounds assayed is restricted and retrospective data-mining is not possible. Therefore, to tackle nontargeted analytical strategies focusing on goals such as wine fingerprinting, high resolution mass spectrometry (HRMS) measurements rely particularly on metabolomics approaches for data assessment [4-7] for which time-of-flight MS (TOFMS) analyzers have been frequently used [8]. Higher resolution mass analysers including orbital ion traps and Fourier transform ion cyclotron resonance (FT-ICR) for providing higher-level confidence in sum formula annotation have also been employed for such investigations and their value for identity confirmation of wine metabolites demonstrated in several studies, particularly in combination with LC-TOFMS where the timescale of the indispensable chromatographic separation is a good match for the speed of the mass analyzer [9-12].

As the range of non-volatile metabolites and related compounds present in wine encompasses a broad range of molecular classes including carbohydrates, amino acids, organic acids, and (poly) phenolic classes including flavonoids, stilbenoids and tannins, liquid chromatographic separation using either reversed-phase (RPLC) or hydrophilic interaction (HILIC) mechanisms is needed to assess the moderately polar and polar metabolite fractions, respectively. For this reason, some groups have extended their focus to two-dimensional LC strategies to approach more comprehensive coverage of these classes $[13,14]$. Such approaches provide unparalleled analytical selectivity particularly when MS is used to support identity confirmation alongside the retention characteristics from both dimensions. Despite these advantages, such strategies are not yet practically feasibly for assessing large cohorts of samples as analysis time and method ruggedness are critical considerations. For this reason, LC-HRMS is considered to be a more pragmatic option for such undertakings. While several different LC-HRMS platforms are now commercially available and supported with suitable software packages, non-targeted characterization of wine remains a nevertheless challenging undertaking for molecular identity confirmation as a significant number of unknown compounds determined via high-resolution MS-based methods have not been described in wine literature [1]. Moreover, focusing primarily on the analysis of the phenolic and polyphenolic compounds in wine is difficult due to the enormous structural diversity of phenols, the large range of possible isomeric structures, the limited number of commercially available standards, and the lack of comprehensive LC-HRMS libraries for confident compound identity confirmation [15]. Thus, optimization of separation and identity confirmation strategies requires development to improve the study of compound-level differences for purposes such as detecting wine adulteration, determination of origin, production and aging processes $[1,13,14,16]$.

One area of emerging analytical interest for non-targeted metabolomics workflows is the use of a generic ion mobility separation nested between the chromatographic and mass spectrometric modules [17-21]. In order to provide unbiased IM-MS coverage of all compounds ionized at the source, this IM separation must be generic (i.e. all compounds must be subject to the IM separation) and provide constant resolution across a wide mass range [22]. IM provides a rapid (millisecond scale) separation of ions according to their mobilities in a gas-filled cell under the influence of a weak electric field. This separation is based on the size, charge and shape of the ion, as well as their ionic interaction with the buffer gas. In this regard, IM can provide additional structural information not determined using LC-HRMS alone, which can be of particular value for the characterization of unknown isomeric compounds. Importantly, a number of interlaboratory comparisons have begun to assess the precision of IM separations under conditions of reproducibility [23,24]. In this regard, of most interest as an identification point is the mobilityderived collision cross section (CCS) calculated for a given ion in a particular neutral drift gas (e.g. nitrogen or helium) via the MasonSchamp extension of the fundamental zero field equation [25]. With a view of the emergence of standardized CCS values to support identity confirmation in metabolomics, this study aimed to assess a broad cohort of traditionally produced wines in a nontargeted workflow and provide an extensive dataset containing LC retention information, accurate mass spectra, and drift timederived CCS values obtained in nitrogen drift gas $\left({ }^{\mathrm{DT}} \mathrm{CCS}_{\mathrm{N} 2}\right)$ to support future work on wine characterization and identification of metabolites present in wine.

Wines representing several different grape varieties and different regions in the Republic of Macedonia were considered within this study. Of particular focus for red wines from this region is the high total phenolic content especially for Vranec grapes. Vranec is the most widely grown and most economically important variety grown in the Republic of Macedonia and is also of importance to the entire Balkan region as an autochthonous variety in Montenegro (known as "Vranac"), and is also cultivated in Serbia and Croatia (Dalmatia). The Povardarie wine region in the Republic of Macedonia is home to more than $80 \%$ of the Macedonian vineyards where other varieties including Staušina (autochthonous Macedonian variety), Kratošija, Pinot Noir, Merlot, Syrah, Kadarka and Cabernet Sauvignon are also grown. An important goal of this study was to provide a meaningful fingerprint of red wines stemming from this region. Using appropriate software tools for alignment and statistical evaluation, the full range of putative compounds determined in this study including retention time, accurate mass, fragment spectra, and ${ }^{\mathrm{DT}} \mathrm{CCS}_{\mathrm{N} 2}$ values representing these varieties are reported with a view to improve the possibilities for identity confirmation of wine metabolites using this approach in future studies. 


\section{Experimental}

\subsection{Chemicals}

Stock solutions of analytical grade phenolic standards (kaempferol, quercetin, myricetin, gallic acid, epicatechin, catechin) were purchased from Sigma-Aldrich (Vienna, Austria) and prepared in water/methanol mixtures. LC-MS grade methanol and water, ammonium formate, and formic acid were also purchased from Sigma-Aldrich.

\subsection{Grape harvesting and wine production}

Grapes from $V$. vinifera red varieties (Cabernet Sauvignon, Frankovka, Merlot, Pettit Verdo, Plavan Mali, Pinot Noir, Syrah, Tempranilo and Vranec) were analysed in this study. Grapes were grown in different wine regions in Republic of Macedonia and all were harvested in September/October 2015, at optimal technological maturity: $18-26^{\circ}$ Brix (levels between 18 and $24^{\circ}$ Brix are desirable as objective criteria for estimating optimal grape maturity). Grapes were collected from 5 to 35 year-old vineyards. The distance between the rows was $1.5 \mathrm{~m}$ and the distance between the vines was $1.0 \mathrm{~m}$. All vineyards were located at attitude from 120 to $800 \mathrm{~m}$. Grapes were manually harvested early in the morning, placed in crates and transported to the wineries for wine production. In total 15 wineries processed the grapes in a same way (Table S2).

The procedure for winemaking, applied in all wineries, was the following: Harvested red grapes from all various varieties were processed using an electrical inox crusher/destemmer, followed by addition of $\mathrm{SO}_{2}$ (ca. $60-80 \mathrm{mg} / \mathrm{L}$ total concentration), in the form of $5 \%$ sulfurous acid. After three to four hours, musts were inoculated with commercial Saccharomyces cerevisiae yeast, which was prepared by rehydrating $(20-30 \mathrm{~g} / 100 \mathrm{~L})$ in water $\left(30^{\circ} \mathrm{C}\right)$ and applied to the musts after $15 \mathrm{~min}$. In addition, nutrients were added in a dose of $40-50 \mathrm{~g} / \mathrm{hL}$ in order to improve the yeast survival during the fermentation conditions.

Maceration of 6-12 days at $23 \pm 2{ }^{\circ} \mathrm{C}$, was applied during that period (alcoholic fermentation) and pumping was applied for all wines two times a day. After the maceration period, wines were separated from the pomace by automatic pressing and stabilized in an inox tank at $4{ }^{\circ} \mathrm{C}$ for a period of two to three weeks. After that period, wines were racked and treated with sulfur dioxide again (30-40 $\mathrm{mg} / \mathrm{L}$ ). The second racking was performed after three to six months of storage, bottled and stored in a cellar at $1-8^{\circ} \mathrm{C}$ for 5 months before analysis.

In total, 42 red wines, from various varieties and various wine locations in Republic of Macedonia (vintage 2016), were produced and analysed. A volume of $0.5 \mathrm{~L}$ of each wine was taken in glass bottles. All wines were sampled directly from the inox tanks placed in the wineries, where they were produced, and kept for 8 months before the analysis.

\subsection{Preparation of samples and quality control protocols}

Wine samples were filtered with nylon membranes (Iso-Disc ${ }^{\mathrm{TM}}$, N-4-4, Nylon, $4 \mathrm{~mm} \times 0.45 \mu \mathrm{m}$, Supelco, Bellefonte, PA, United States). Filtered samples were diluted 1:10 with $10 \mathrm{mM}$ ammonium formate solution ( $\mathrm{pH}$ 3.75). Samples were stored at $6{ }^{\circ} \mathrm{C}$ in the autosampler tray when awaiting analysis. Pooled samples were prepared by combining equal volumes of all samples to be measured within a single batch. Additional quality control samples measured included filtered blanks (i.e. containing the ammonium formate solution) and wine samples spiked with authentic phenolic standards. All samples were analysed in a randomized order and were interspersed with injections of a QC/filtered blank pair and a spiked/unspiked wine pair. Pairs were measured after every sixth sample (i.e. alternating throughout the sequence).

\subsection{HPLC-MS instrumentation}

An Agilent 1290 Infinity II LC system was coupled to an Agilent 6560 IMS-QTOF mass spectrometer equipped with an Agilent G1607A dual Jetstream ESI source, and an upgraded ion mobility alternate gas kit with electronic drift gas pressure control. During analysis, a solution containing calibrant masses (purine and hexakis- $(1 \mathrm{H}, 1 \mathrm{H}, 3 \mathrm{H}$-tetrafluoro-pentoxy) phosphazene) was combined with the column effluent via a secondary capillary pump (Agilent 1100 series) and T-piece with a flow rate of $10 \mu \mathrm{L} / \mathrm{min}$ between column exit and the ESI source. The secondary sprayer of the ion source was completely closed to gas and liquid flow for all measurements. Sample injection was performed by a Gerstel Dual Rail MPS 2 robot (Mülheim an der Ruhr, Germany) with a loop size of $5 \mu \mathrm{L}$.

\subsection{HPLC $\times I M S-T O F M S$ conditions}

The chromatographic method was adapted from previous work $[26,27]$. Briefly, HPLC separations were performed at a temperature of $30^{\circ} \mathrm{C}$ using a Zorbax Eclipse Plus C18 Rapid Resolution column $\left(2.1 \times 50 \mathrm{~mm}, 1.8 \mu \mathrm{m} d_{p}\right)$ and a reversed-phase mobile phase gradient. Eluent A contained $0.1 \% \mathrm{v} / \mathrm{v}$ formic acid in water, and Eluent B was methanol. Using a solvent flow rate of $250 \mu \mathrm{L} / \mathrm{min}$, an initial composition of $98 \%$ A was held for $2.4 \mathrm{~min}$, followed by a compositional gradient from 2 to $40 \% \mathrm{~B}$ in $2.4-18 \mathrm{~min}$, then increasing to $70 \%$ from 18 to $20.4 \mathrm{~min}$. This composition was held for $0.6 \mathrm{~min}$ prior to returning to $2 \% \mathrm{~B}$ and holding for $3 \mathrm{~min}$ (total run time of $24 \mathrm{~min}$ ).

Nitrogen was used as drying gas at a temperature of $360^{\circ} \mathrm{C}$, a sheath gas temperature of $225^{\circ} \mathrm{C}$ and a sheath gas flow rate of $13 \mathrm{~L} /$ $\min$. The nebulizer gas pressure was $30 \mathrm{psi}$, the MS capillary voltage was $3500 \mathrm{~V}$, the nozzle voltage $500 \mathrm{~V}$ and the fragmentor was set to $275 \mathrm{~V}$. Following tuning in the $2 \mathrm{GHz}$ extended dynamic range mode with a mass range of $50-1700 \mathrm{~m} / \mathrm{z}$, mass calibration was undertaken immediately prior to measurements using the supplied tune mixture of the manufacturer. All voltage polarities were set according to the ionization mode.

The IM trapping funnel was operated with an accumulation time of $10000 \mu$ s and released packages of ions every 45 ms with a trap release time of $150 \mu$ s set within the software. The drift tube was operated with an absolute entrance voltage of $1574 \mathrm{~V}$ and an exit voltage of $224 \mathrm{~V}$ with a drift tube pressure of 3.95 Torr and a temperature of $25^{\circ} \mathrm{C}$ using high purity nitrogen as the collision gas. The acquisition settings were adjusted to yield 30 ion mobility transients per frame corresponding to 0.7 ion mobility frames per second.

\subsection{Post-processing of data}

Data collected were firstly post-processed for online accurate mass calibration in the software tool provided by the instrument manufacturer using the reference masses of calibrant ions. Data files were then subject to smoothing [28] in the chromatographic and drift time domains with kernel sizes of 5 and 3, respectively. The ${ }^{\mathrm{DT}} \mathrm{CCS}_{\mathrm{N} 2}$ values for ions measured in wine samples were determined using a single-field calculation facilitated by the measurement of a series of calibrant ions with conditional reference ${ }^{\mathrm{DT}} \mathrm{CCS}_{\mathrm{N} 2}$ values representing the best estimate of the true values [24]. Finally, data files were trimmed in the IM Browser to reduce the searchable $m / z$ vs drift time space according to knowledge of 
conformational ordering of molecules (see Supporting Information S1).

\subsection{Molecular feature finding and alignment}

Data files were then assessed using MassHunter Mass Profiler and the IM Browser Software (B08.00). Data files were evaluated in batches according to wine type in a non-targeted workflow. For the molecular feature finding step, the common organic molecules isotope model was used, the charge state was limited to between \pm 1 and \pm 2 , a minimum extraction threshold of 50 counts (spectral abundance) set, and molecular features were restricted to retention times between 2 and $20 \mathrm{~min}$. Intersample molecular feature alignment used retention time matching of $\pm 0.20 \mathrm{~min}$, and accurate $\mathrm{m} / \mathrm{z}$ of $10 \mathrm{ppm} \pm 2 \mathrm{mDa}$. To enable varietal group fingerprinting, resultant molecular feature lists were further filtered by frequency within a given variety (i.e. presence in $\geq 2$ samples within the variety). These lists were further refined by Q-Score $(\geq 70)$ and a minimum cut-off abundance of 5000 (average of the monoisotopic ion peak volume). ${ }^{\mathrm{DT}} \mathrm{CCS}_{\mathrm{N} 2}$ values of the authentic standards measured using an established standardized method [24] were added to a compound library for supporting identification confirmation via Agilent PCDL Manager (B.08.00).

\subsection{Statistical assessments}

Feature summaries (compound exchange format, *.cef) for all samples were imported into MassHunter Mass Profiler Professional (14.2) to allow multivariate statistical assessments according to variety. Varieties well-represented within the cohort of wine samples (Vranec, Merlot, Cabernet Sauvignon, and Pinot Noir) were assessed alongside the pooled QC and blank QC replicates. All alignment tolerances were maintained from the initial software extraction step, except for the mass alignment which was increased to $\pm 15 \mathrm{ppm}$ to allow for features with low ion counting statistics to be better aligned across different varieties. Furthermore, a minimum of two ions (isotopologues) was required for further consideration as a molecular feature (putative compound).

\section{Results and discussion}

\subsection{Level 2 identity confirmation using retention time, ${ }^{D T} C C S_{N 2}$ and} accurate mass

To firstly establish that the generic drift tube IM separation can provide CCS values in agreement with standardized stepped- and single-field measurements of relevant analytical standards for this application, a series of analytical standards were measured using direct infusion approaches and using the established LC $\times$ IMTOFMS method. The single-field approach utilized on this instrument represents a derivation of the conventional Mason-Schamp equation and relies on a single measurement of a series of calibrant ions, for which ${ }^{\mathrm{DT}} \mathrm{CCS}_{\mathrm{N} 2}$ values were established in a recent study [24]. Comparison of values derived from the conventional stepped-field approach with single-field determination revealed an average absolute bias of $0.41 \%$ across positive and negative ionization modes. This value is consistent with the average bias of $0.54 \%$ recently reported in an interlaboratory study [24].

In addition to the excellent agreement between results obtained for the measurement of standards, agreement with results from spiked wine samples also demonstrated the excellent measurement precision $(<0.3 \%)$ and low bias between the standardized infusion and chromatographic results (average of $0.15 \%$ ) as well as the excellent precision across the sequences $(<0.05 \%)$, indicating that the wine matrix had little or no influence on the accuracy of ${ }^{\mathrm{DT}} \mathrm{CCS}_{\mathrm{N} 2}$ determination using this platform (Table $1 \&$ Supporting

Table 1

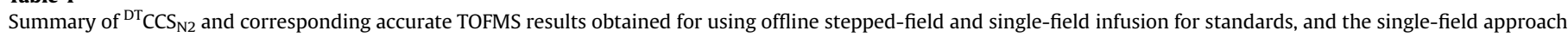
for chromatographic measurements.

\begin{tabular}{|c|c|c|c|c|c|c|c|c|c|c|c|}
\hline \multirow[t]{3}{*}{ Compound } & \multirow[t]{3}{*}{ Formula } & \multirow[t]{3}{*}{$t_{R}(\min )$} & \multirow[t]{3}{*}{ Ion Species } & \multicolumn{6}{|c|}{${ }^{\mathrm{DT}} \mathrm{CCS}_{\mathrm{N} 2}\left(\AA^{2}\right)$} & & \\
\hline & & & & \multicolumn{3}{|c|}{$\begin{array}{l}\text { Infusion measurements (stepped \& single- } \\
\text { field) }\end{array}$} & \multicolumn{3}{|c|}{$\begin{array}{l}\text { Online single-field measurements } \\
\text { (spiked wine sample) }\end{array}$} & \multicolumn{2}{|c|}{ Mass Accuracy } \\
\hline & & & & $\begin{array}{l}\text { Stepped-field } \\
\text { (standard) }\end{array}$ & $\begin{array}{l}\text { Single-field } \\
\text { (standard) }\end{array}$ & $\begin{array}{l}\text { Bias (Single } \\
\text { vs Stepped) }\end{array}$ & $\begin{array}{l}\text { Average } \\
(n=3)\end{array}$ & \%RD & $\begin{array}{l}\text { Single-field } \\
\text { Bias (Std. vs } \\
\text { Wine) }\end{array}$ & $\begin{array}{l}\text { Average } \\
(n=3)\end{array}$ & $\begin{array}{l}\text { Error } \\
(\mathrm{ppm})\end{array}$ \\
\hline Gallic acid & $\mathrm{C}_{7} \mathrm{H}_{6} \mathrm{O}_{5}$ & 2.16 & {$[\mathrm{M}-\mathrm{H}]^{-}$} & 126.1 & 124.8 & $-0.99 \%$ & 125.0 & $0.026 \%$ & $0.13 \%$ & 169.0149 & $4.3^{\mathrm{b}}$ \\
\hline \multirow[t]{3}{*}{ Kaempherol } & $\mathrm{C}_{15} \mathrm{H}_{10} \mathrm{O}_{6}$ & 20.3 & {$[\mathrm{M}-\mathrm{H}]^{-}$} & 163.8 & 162.7 & $-0.65 \%$ & 162.3 & $0.034 \%$ & $-0.28 \%$ & 285.0409 & 1.4 \\
\hline & & & {$[\mathrm{M}+\mathrm{H}]^{+}$} & 163.6 & 163.2 & $-0.27 \%$ & 162.9 & $0.028 \%$ & $-0.13 \%$ & 287.0560 & 3.5 \\
\hline & & & {$[\mathrm{M}+\mathrm{Na}]^{+}$} & 182.8 & 182.0 & $-0.44 \%$ & n.d. & n.d. & n.d. & n.d & n.d. \\
\hline \multirow[t]{3}{*}{ Myricetin } & $\mathrm{C}_{15} \mathrm{H}_{10} \mathrm{O}_{8}$ & 17.1 & {$[\mathrm{M}-\mathrm{H}]^{-}$} & 168.4 & 167.4 & $-0.61 \%$ & 167.1 & $0.024 \%$ & $-0.18 \%$ & 317.0274 & $-9.0^{\mathrm{b}}$ \\
\hline & & & {$[\mathrm{M}+\mathrm{H}]^{+}$} & 171.6 & 171.4 & $-0.10 \%$ & 171.2 & $0.015 \%$ & $-0.10 \%$ & 319.0457 & 2.7 \\
\hline & & & {$[\mathrm{M}+\mathrm{Na}]^{+}$} & 190.3 & 189.4 & $-0.48 \%$ & n.d. & n.d. & n.d. & n.d & n.d. \\
\hline \multirow[t]{4}{*}{ Catechin } & $\mathrm{C}_{15} \mathrm{H}_{14} \mathrm{O}_{6}$ & 8.39 & {$[\mathrm{M}-\mathrm{H}]^{-}$} & 158.1 & 156.9 & $-0.73 \%$ & 157.3 & $0.029 \%$ & $0.24 \%$ & 289.0709 & $-3.0^{\mathrm{b}}$ \\
\hline & & & {$[\mathrm{M}+\mathrm{H}]^{+}$} & $161.6^{\mathrm{a}}$ & 162.4 & $0.47 \%$ & 162.3 & $0.014 \%$ & $-0.021 \%$ & 291.0873 & $-3.5^{\mathrm{b}}$ \\
\hline & & & {$[\mathrm{M}+\mathrm{H}]^{+}$} & $170.1^{\mathrm{a}}$ & 168.6 & $-0.88 \%$ & 168.1 & $0.015 \%$ & $-0.28 \%$ & 291.0870 & 2.5 \\
\hline & & & {$[\mathrm{M}+\mathrm{Na}]^{+}$} & 180.5 & 180.2 & $-0.18 \%$ & n.d. & n.d. & n.d. & n.d & n.d. \\
\hline \multirow[t]{4}{*}{ Epicatechin } & $\mathrm{C}_{15} \mathrm{H}_{14} \mathrm{O}_{6}$ & 11.0 & {$[\mathrm{M}-\mathrm{H}]^{-}$} & 158.4 & 157.1 & $-0.78 \%$ & 157.2 & $0.031 \%$ & $0.042 \%$ & 289.0716 & $-0.58^{b}$ \\
\hline & & & {$[\mathrm{M}+\mathrm{H}]^{+}$} & $161.5^{\mathrm{a}}$ & 162.4 & $0.55 \%$ & 162.2 & $0.016 \%$ & $-0.080 \%$ & 291.0876 & $-4.4^{\mathrm{b}}$ \\
\hline & & & {$[\mathrm{M}+\mathrm{H}]^{+}$} & $169.8^{\mathrm{a}}$ & 168.4 & $-0.82 \%$ & 168.1 & $0.0034 \%$ & $-0.19 \%$ & 291.0872 & $-3.2^{\mathrm{b}}$ \\
\hline & & & {$[\mathrm{M}+\mathrm{Na}]^{+}$} & 177.5 & 177.0 & $-0.27 \%$ & & n.d. & n.d. & n.d & n.d. \\
\hline \multirow[t]{3}{*}{ Naringenin } & $\mathrm{C}_{15} \mathrm{H}_{12} \mathrm{O}_{5}$ & 19.4 & {$[\mathrm{M}-\mathrm{H}]^{-}$} & 164.9 & 163.8 & $-0.67 \%$ & 163.7 & $0.028 \%$ & $-0.069 \%$ & 271.0610 & -0.86 \\
\hline & & & {$[\mathrm{M}+\mathrm{H}]^{+}$} & 163.8 & 163.8 & $<0.001 \%$ & 163.4 & $0.040 \%$ & $-0.25 \%$ & 273.0765 & 2.9 \\
\hline & & & {$[\mathrm{M}+\mathrm{Na}]^{+}$} & 181.3 & 180.6 & $-0.41 \%$ & & n.d. & n.d. & n.d & n.d. \\
\hline \multirow[t]{3}{*}{ Quercetin } & $\mathrm{C}_{15} \mathrm{H}_{10} \mathrm{O}_{7}$ & 19.3 & {$[\mathrm{M}-\mathrm{H}]^{-}$} & 165.5 & 164.6 & $-0.56 \%$ & 164.6 & $0.011 \%$ & $-0.0060 \%$ & 301.0334 & $-6.8^{\mathrm{b}}$ \\
\hline & & & {$[\mathrm{M}+\mathrm{H}]^{+}$} & 167.7 & 167.7 & $-0.036 \%$ & 167.4 & $0.0060 \%$ & $-0.18 \%$ & 303.0507 & 2.7 \\
\hline & & & {$[\mathrm{M}+\mathrm{Na}]^{+}$} & 186.6 & 185.9 & $-0.41 \%$ & & n.d. & n.d. & n.d & n.d. \\
\hline Ferulic acid & $\mathrm{C}_{10} \mathrm{H}_{10} \mathrm{O}_{4}$ & 12.91 & {$[\mathrm{M}-\mathrm{H}]^{-}$} & 139.7 & 139.7 & $-0.021 \%$ & 139.9 & $<0.001 \%$ & $0.14 \%$ & 193.0507 & 0.69 \\
\hline
\end{tabular}

n.d. not detected.

a The drift times of conformers were manually determined for the stepped-field calculation.

b Denotes significant detector saturation. 
Information Figure S2). The differences in ${ }^{\mathrm{DT}} \mathrm{CCS}_{\mathrm{N} 2}$ values observed between sodiated and protonated molecular ions were mostly between 9 and 12\%, and were consistent with an expected increase arising due to the change in charge carrier.

Precision and trueness of the $m / z$ measurements (accuracy) were also found to be generally very good except in cases where detector saturation was apparent particularly in the negative ionization mode. In such cases, the mass error and precision increased from $<3 \mathrm{ppm}$ to higher for the standards used in this study. This occurred for some of the standard compounds used in this study that are present in very high concentrations in red wine (i.e. catechin, epicatechin, and quercetin). The probability of reaching saturation of the TOF detector is increased in the IM-TOFMS mode due to the change from a continuous ion transmission into discrete ion packages reaching the detector in locally high concentrations. Without use of a suitable software-based data processing to correct such saturation effects [29], this limits the total dynamic range that can be studied in this measurement mode [30]. In a practical sense, this means that care must be taken to choose a sample dilution level that is sufficient to reduce the number of saturation events during the chromatographic run, but also does not effectively dissipate signals arising from low abundance compounds that may be of interest in fingerprinting workflows. Nevertheless, the majority of compounds were detected at levels below that where detector saturation effects were observed to influence mass accuracy meaning that retention, accurate ${ }^{{ }^{D T}} \mathrm{CCS}_{\mathrm{N} 2}$ and TOF mass spectra can be considered as reliable identification points for each software-extracted molecular feature in the wine metabolomics workflow.

\subsection{Assessment of quality control samples}

Having established the accuracy and control of measurement repeatability with respect to the ion mobility separation and mass accuracy for several standard phenolic compounds, variability within the measurement sequences was assessed within a nontargeted context by software-based extraction of the pooled QC and procedural blank measurements. Comparison of base peak chromatograms and data for standards spiked in wine samples recorded during the $22 \mathrm{~h}$ measurement sequence indicated the absence of substantial signal drift across the sequence (Fig. 1). Procedural blanks measured throughout the measurement sequence were batch software extracted using the same settings as all sample groups and revealed only 23 significant molecular
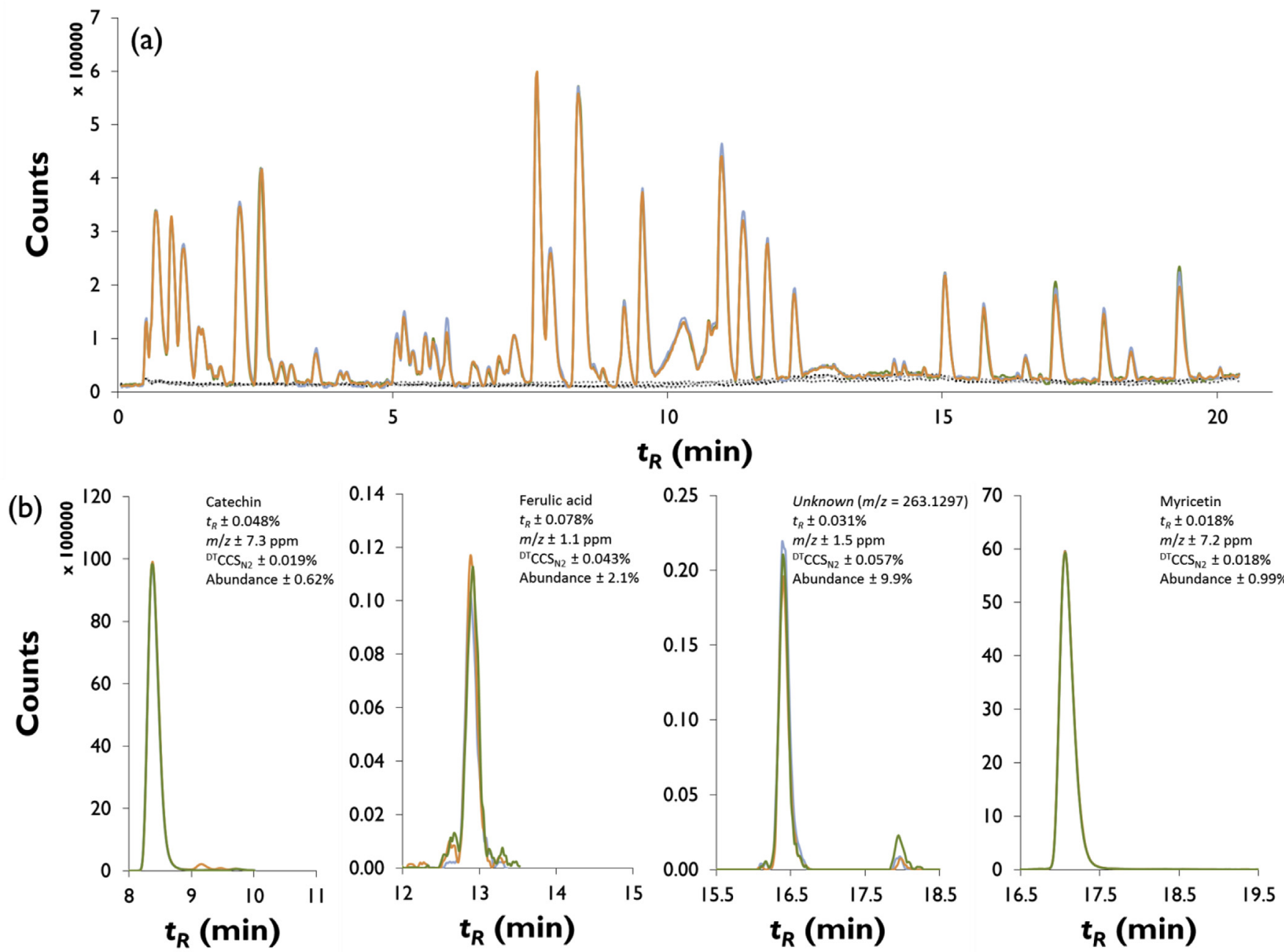

21

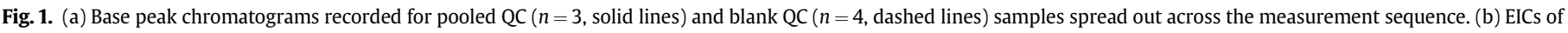
standard compounds spiked into wine recorded during the measurement sequence ( $n=3$, injected at evenly spaced intervals across the $22 \mathrm{~h}$ sequence). 
features using a minimum abundance of 5000 (total ion volume), group frequency of $\geq 2$, and a Q-Score cutoff of 70 . In comparison, assessment of the pooled QC sample revealed 3466 significant molecular features using the same settings.

As no studies have yet demonstrated that relative quantification using LC $\times$ IM-TOFMS via reliable fold-change determination with full method validation, the complete set of software-extracted molecular features from the pooled QCs was used to estimate the variability of molecular feature abundance in this group to inform further comparisons between varieties. Lower \%RSD for the abundance correlated well with increasing total volume ion abundance and employment of a lower cut-off of 10000 as total monoisotopic ion volume yielded a set of 2195 molecular features for which $92 \%$ of the features had \%RSD (coefficient of variance) of $<40 \%$ across three technical replicates (Fig. 2). For this reason, this abundance cut-off was used for comparisons of the major wine groups and subsequent fingerprinting.
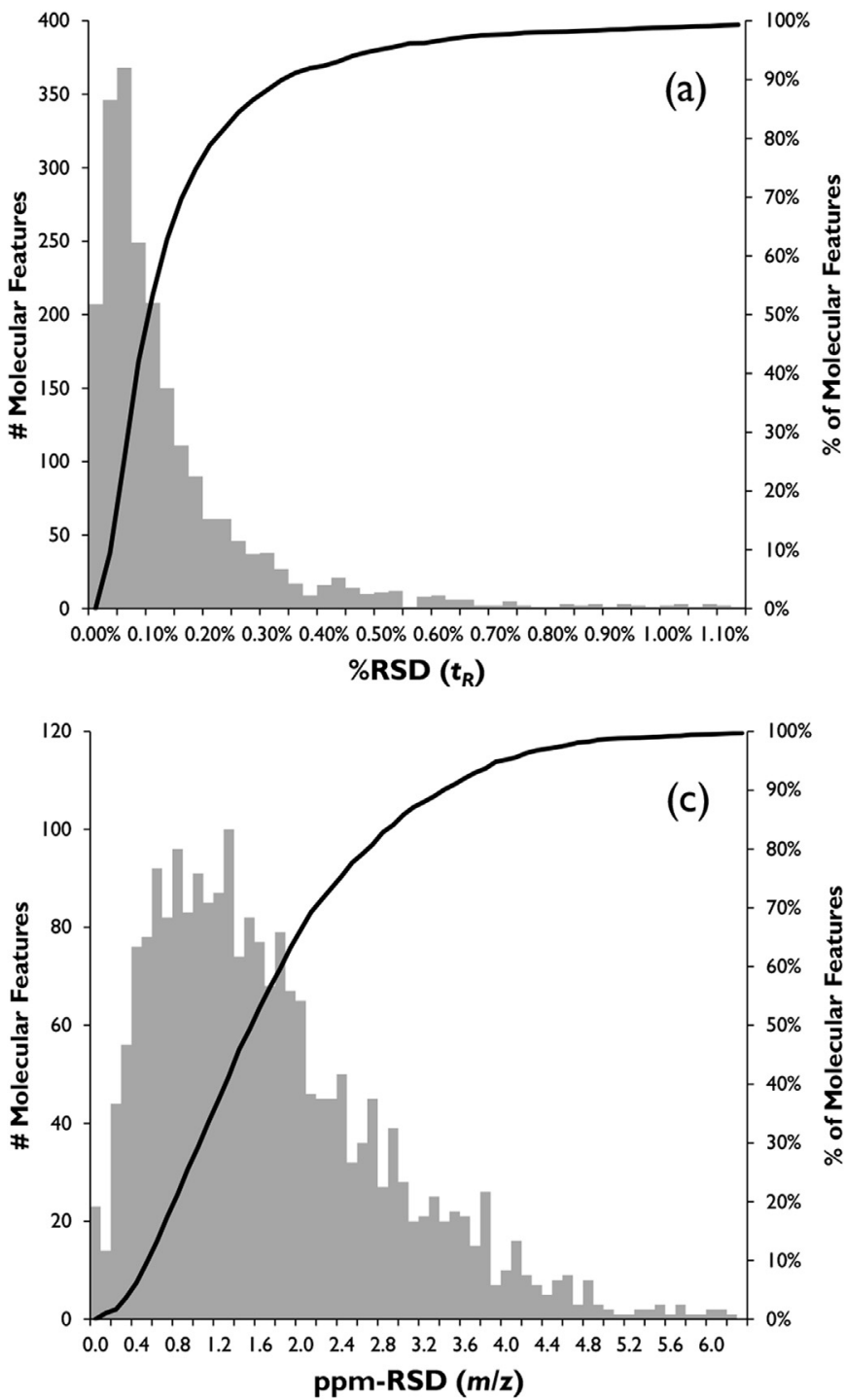

\subsection{Annotation of metabolites}

Use of CCS values as an identification point for metabolomics to aid with identity confirmation is an emerging area of analytical interest. Use of CCS values requires not only detailed knowledge of the calibration procedure and within-lab repeatability of measurements, but also interlaboratory studies of reproducibility to finally provide estimates of the uncertainty associated with the mobility measurand. A significant study from Paglia et al. [23] was the first to make such an undertaking for commercial instruments comparing travelling wave IM-MS measurements of both metabolites and lipids measured across three different labs. More recently, the study of Stow et al. [24] demonstrated that agreement across multiple laboratories (precision under reproducibility condition) is below $1 \%$ for a wide range of metabolites and other compound classes using this model of instrument. While CCS is a promising candidate as an identification point for non-targeted strategies, the high degree of correlation with $\mathrm{m} / \mathrm{z}$ and the lack of
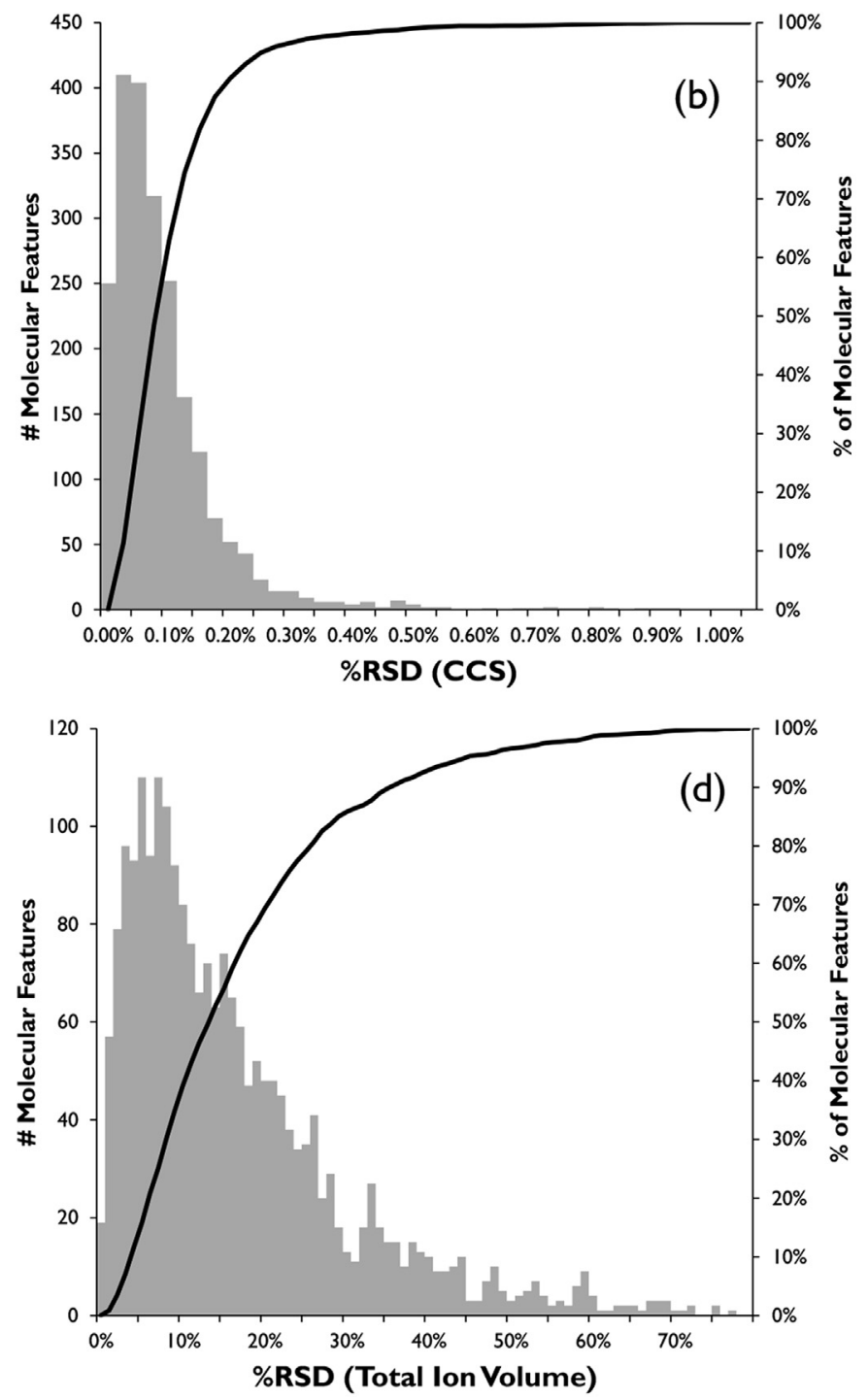

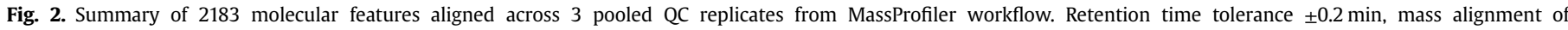

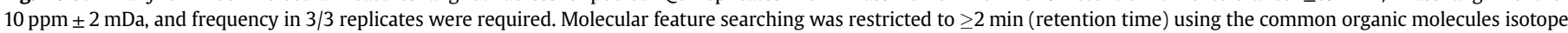

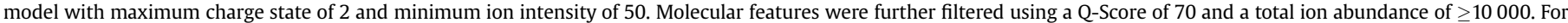
interpretation, the black line corresponds to the RHS y-axis and the grey columns to the LHS. 
accurate models to predict true CCS values in nitrogen prevent unequivocal identity confirmation based upon these two parameters alone. With this in mind, collecting traceable and accurate CCS values for unknown compounds requires careful reporting of experimental conditions (including sample preparation), and scrupulous use of retention time and accurate mass for correct alignment and fusion of positive and negative mode datasets.

In addition to the range of phenolic standards investigated in this study (see Table 1), some putative compounds from previous studies of red wines (particularly Vranec) were used to support tentative identifications according to accurate mass spectra (see Supporting Information Table S3). Of particular interest in this type of dataset was the appearance of fragments associated with intact phenolic metabolites, which could be initially aligned by the retention profile. In addition to the well-known in-source fragmentation, the possibility of post-drift tube fragmentation is apparent due to the use of an RF field to refocus the ions in the rear funnel region of the instrument. Within IM-TOFMS datafiles, insource fragmentation can be distinguished from post-drift tube fragmentation by inspection of the drift time of the suspected fragment. Exemplary data are shown for standards investigated in this study and for tentatively identified glycosylated compounds, whereby fragment EICs and the drift spectra are shown to align with the corresponding precursor in both dimensions. In-source fragmentation can be considered to be a greater problem for nontargeted assessments as rules for identifying this behavior must be pre-determined for the molecular feature finding process. Conversely, post-drift tube fragmentation will complicate data processing, but can be used to increase confidence in annotation of fragile metabolites via the combination of $t_{R}$ and $t_{d}$ alignment of fragments with precursors.

Other metabolites that could be tentatively identified based on mass spectra and literature included grape reaction products (Sglutathionyl caftaric acid and its derivatives [31,32]), along with several phenolic compounds consistent with previous literature studying similar wines (e.g. stilbenes, flavan-3-ols, anthocyanins, acetylglucosides, and p-coumarylglucosides [33-35]). Additionally, ${ }^{\mathrm{DT}} \mathrm{CCS}_{\mathrm{N} 2}$ values for ions of some compounds could be directly compared to previous studies including quercetin, catechin and kaempferol, which were found to have biases of $<0.4 \%$ compared to recently published values [36].

\subsection{Generation of varietal fingerprints}

As non-targeted extraction strategies involve a molecular feature finding step which is often in combination with binning and intersample alignment of features, there are some variables that can have an influence on final results prior to statistical assessments. One example of note for the treatment of LC $\times$ IMTOFMS datafiles is the software-based extraction of molecular features from samples representing a wide variety of sample groups or classes where abundances can substantially influence the signal quality at low concentrations (i.e. poor ion counting statistics), or approach detector saturation issues at very high levels. For this reason, wine samples were considered in this study within the software according to wine variety for the initial feature finding process to ensure that the first list of putative molecular features for a given variety was solely a representation of that variety. Subsequent assessments requiring statistical comparisons of varieties involved a secondary alignment of features according to tolerance settings for retention time, mass accuracy and CCS.

Initial assessment of the results by principal component analysis indicated the good repeatability for the quality control groups and the ability to broadly classify wines according to variety. The Vranec wines are readily distinguished from all other major groups, which correlates well with their characteristic phenolic profile studied in previous work [33-35]. Pinot Noir samples were also readily distinguished from other wine varieties, but these results should be carefully interpreted due to the limited number of wines (four) available for this study (see Supporting Information Figure S3).

As data were not normalized and variations between geographic regions, maceration time, altitude and soil types could not be exhaustively considered in this set of samples, the variability within the Cabernet Sauvignon and Merlot wines appears be more significant and therefore limits interpretation when using the entire set of putative compounds and their raw abundances. Thus, in order for a set of putative compounds to be used as an authentic fingerprint, appearance of a molecular feature in at least $75 \%$ of samples within a variety was required, variations in abundance exceeding 50\% within a variety were excluded, a fold-change of 3 taken as a cut-off for paired varietal comparisons and a one-way analysis of variance (ANOVA) test employed to filter down to molecular features characteristic for the variety as supported by principal component analysis and hierarchical clustering

Table 2

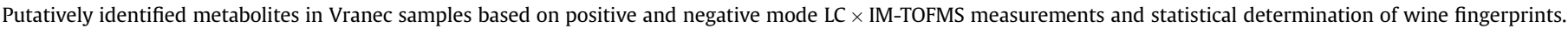

\begin{tabular}{|c|c|c|c|c|c|c|c|c|c|c|c|c|c|c|c|}
\hline \multicolumn{8}{|c|}{ Negative Mode } & \multicolumn{8}{|c|}{ Positive Mode } \\
\hline$\#$ & $t_{R}(\min )$ & $m / z$ & Freq. & Q Score & ${ }^{\mathrm{DT}} \mathrm{CCS}_{\mathrm{N} 2}\left(\AA^{2}\right)$ & $\begin{array}{l}\text { Assumed } \\
\text { Species }\end{array}$ & $\begin{array}{l}\text { Fragments } \\
\& \text { adducts }\end{array}$ & $t_{R}(\min )$ & ${ }^{\mathrm{DT}} \mathrm{CCS}_{\mathrm{N} 2}\left(\AA^{2}\right)$ & $\begin{array}{l}\text { Assumed } \\
\text { Species }\end{array}$ & $m / z$ & Freq. & Q Score & $\begin{array}{l}\text { Fragments } \\
\& \text { adducts }\end{array}$ & $\begin{array}{l}\text { Putative } \\
\text { Formula/ID }\end{array}$ \\
\hline (a) & 12.59 & 461.1083 & 12 & 77.6 & 207.5 & {$[\mathrm{M}-2 \mathrm{H}]^{-}$} & $\begin{array}{l}{\left[\mathrm{M}-2 \mathrm{H}+\mathrm{H}_{2} \mathrm{O}\right]^{-} ;} \\
{[\mathrm{M}-2 \mathrm{H}-\text { glc }]^{-}}\end{array}$ & 12.61 & 207.1 & {$[\mathrm{M}]^{+}$} & 463.1236 & 12 & 100 & - & $\begin{array}{l}\text { peonidin } \\
\text { 3-glucoside }\end{array}$ \\
\hline (b) & 8.34 & 359.1348 & 12 & 100 & 173.8 & {$[\mathrm{M}-\mathrm{H}]^{-}$} & - & 8.35 & 184.4 & {$[\mathrm{M}+\mathrm{Na}]^{+}$} & 383.1311 & 12 & 100 & - & C16H23 O9 \\
\hline (c) & 17.84 & 385.1498 & 12 & 100 & 183.8 & {$[\mathrm{M}-\mathrm{H}]^{-}$} & 223.0976 & 17.85 & 196.5 & {$[\mathrm{M}+\mathrm{Na}]^{+}$} & 409.1465 & 12 & 100 & - & C18H26 O9 \\
\hline (d) & 10.86 & 415.2186 & 12 & 100 & 198.1 & {$[\mathrm{M}-\mathrm{H}]^{-}$} & 191.0338 & 10.85 & 198.2 & {$[\mathrm{M}+\mathrm{H}]^{+}$} & 417.2340 & 12 & 100 & - & C17H36 011 \\
\hline (e) & 12.74 & 385.1865 & 12 & 100 & 204.4 & {$[\mathrm{M}-\mathrm{H}]^{-}$} & 149.0444 & 12.74 & 204.4 & {$[\mathrm{M}+\mathrm{Na}]^{+}$} & 409.1826 & 12 & 99.6 & - & С19H30 O8 \\
\hline (f) & 7.70 & 343.1036 & 12 & 100 & 183.1 & {$[\mathrm{M}-\mathrm{H}]^{-}$} & - & 7.70 & 187.2 & {$[\mathrm{M}+\mathrm{Na}]^{+}$} & 367.1001 & 12 & 100 & - & C15H20 O9 \\
\hline (g) & 7.84 & 315.0645 & 11 & 100 & 164.7 & {$[\mathrm{M}-\mathrm{H}]^{-}$} & - & 7.88 & 171.8 & {$[\mathrm{M}+\mathrm{Na}]^{+}$} & 339.0623 & 10 & 100 & - & C20H12 O4 \\
\hline (h) & 12.31 & 487.0846 & 12 & 99 & 212.5 & {$[\mathrm{M}-\mathrm{H}]^{-}$} & 299.0556 & 12.32 & 210.8 & {$[\mathrm{M}+\mathrm{H}]^{+}$} & 489.1004 & 12 & 100 & 321.0597 & C23H20 012 \\
\hline \multirow[t]{2}{*}{ (i) } & 9.83 & 358.1285 & 12 & 100 & 176.9 & {$[\mathrm{M}-\mathrm{H}]^{-}$} & - & 9.84 & 185.7 & {$[\mathrm{M}+\mathrm{H}]^{+}$} & 360.1441 & 12 & 100 & - & C16H23 O9 \\
\hline & & & & & & & & 9.83 & 194.2 & {$[\mathrm{M}+\mathrm{H}]^{+}$} & 360.1440 & 12 & 100 & - & C16H23 O9 \\
\hline (j) & 12.12 & 358.1281 & 12 & 100 & 177.0 & {$[\mathrm{M}-\mathrm{H}]^{-}$} & - & 12.13 & 184.6 & {$[\mathrm{M}+\mathrm{H}]^{+}$} & 360.1442 & 12 & 97.4 & - & C16H23 O9 \\
\hline (k) & 8.83 & 367.1599 & 11 & 85.5 & 192.5 & {$[\mathrm{M}-\mathrm{H}]^{-}$} & - & 8.83 & 186.4 & {$[\mathrm{M}+\mathrm{Na}]^{+}$} & 391.1566 & 12 & 99.6 & - & C15H28 010 \\
\hline (l) & 10.19 & 358.1286 & 12 & 100 & 177.0 & {$[\mathrm{M}-\mathrm{H}]^{-}$} & - & 10.20 & 185.6 & {$[\mathrm{M}+\mathrm{H}]^{+}$} & 360.1441 & 12 & 100 & - & $\mathrm{C} 16 \mathrm{H} 23 \mathrm{O}$ \\
\hline (m) & 14.17 & 372.1450 & 12 & 100 & 180.0 & {$[\mathrm{M}-\mathrm{H}]^{-}$} & 334.1754 & 14.18 & 188.0 & {$[\mathrm{M}+\mathrm{H}]^{+}$} & 374.1607 & 12 & 100 & - & C17H25 O9 \\
\hline (n) & 11.93 & 358.1282 & 12 & 98.4 & 177.0 & {$[\mathrm{M}-\mathrm{H}]^{-}$} & - & 11.95 & 184.4 & {$[\mathrm{M}+\mathrm{H}]^{+}$} & 360.1443 & 12 & 95.1 & - & $\mathrm{C} 16 \mathrm{H} 23 \mathrm{O}$ \\
\hline (o) & 10.34 & 490.2105 & 12 & 100 & 207.6 & {$[\mathrm{M}-\mathrm{H}]^{-}$} & - & 10.35 & 210.8 & {$[\mathrm{M}+\mathrm{H}]^{+}$} & 492.2259 & 12 & 100 & - & C19H39 $012 \mathrm{~S}$ \\
\hline
\end{tabular}


Table 3

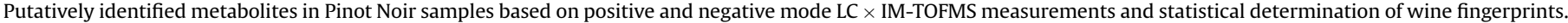

\begin{tabular}{|c|c|c|c|c|c|c|c|c|c|c|c|c|c|c|c|}
\hline \multicolumn{8}{|c|}{ Negative Mode } & \multicolumn{8}{|c|}{ Positive Mode } \\
\hline \# & $t_{R}(\min )$ & $m / z$ & Freq. & Q Score & ${ }^{\mathrm{DT}} \mathrm{CCS}_{\mathrm{N} 2}\left(\AA^{2}\right)$ & $\begin{array}{l}\text { Assumed } \\
\text { Species }\end{array}$ & $\begin{array}{l}\text { Fragments } \\
\& \text { adducts }\end{array}$ & $t_{R}(\min )$ & ${ }^{\mathrm{DT}} \mathrm{CCS}_{\mathrm{N} 2}\left(\AA^{2}\right)$ & $\begin{array}{l}\text { Assumed } \\
\text { Species }\end{array}$ & $m / z$ & Freq. & Q Score & $\begin{array}{l}\text { Fragments } \\
\& \text { adducts }\end{array}$ & $\begin{array}{l}\text { Putative } \\
\text { Formula/ID }\end{array}$ \\
\hline (a) & 8.38 & 373.0236 & 4 & 100 & 171.9 & {$[\mathrm{M}-\mathrm{H}]^{-}$} & - & 8.40 & 192.1 & {$[\mathrm{M}+\mathrm{H}]^{+}$} & 375.0385 & 4 & 99.2 & - & C10H14 015 \\
\hline (b) & 7.32 & 382.0999 & 4 & 100 & 176.6 & {$[\mathrm{M}-\mathrm{H}]^{-}$} & - & 7.33 & 189.3 & {$[\mathrm{M}+\mathrm{H}]^{+}$} & 384.1158 & 4 & 100 & 252.0721 & C28H15 O2 \\
\hline (c) & 6.84 & 383.1555 & 4 & 99.5 & 191.7 & {$[\mathrm{M}-\mathrm{H}]^{-}$} & - & 6.84 & 188.1 & {$[\mathrm{M}+\mathrm{Na}]^{+}$} & 407.1539 & 4 & 100 & - & $\mathrm{C} 15 \mathrm{H} 28 \mathrm{O} 11$ \\
\hline (d) & 8.41 & 401.2035 & 4 & 100 & 190.9 & {$[\mathrm{M}-\mathrm{H}]^{-}$} & - & 8.41 & 193.4 & {$[\mathrm{M}+\mathrm{H}]^{+}$} & 403.2189 & 4 & 100 & - & C16H34 011 \\
\hline (e) & 12.42 & 410.1309 & 4 & 100 & 203.0 & {$[\mathrm{M}-\mathrm{H}]^{-}$} & - & 12.42 & 200.0 & {$[\mathrm{M}+\mathrm{H}]^{+}$} & 412.1460 & 4 & 100 & - & - \\
\hline (f) & 6.30 & 416.1552 & 4 & 100 & 199.3 & {$[\mathrm{M}-\mathrm{H}]^{-}$} & - & 6.27 & 193.6 & {$[\mathrm{M}+\mathrm{H}]^{+}$} & 418.1711 & 4 & 100 & - & $\mathrm{C} 15 \mathrm{H} 29 \mathrm{O} 13$ \\
\hline (g) & 17.36 & 453.1338 & 4 & 100 & 222.1 & {$[\mathrm{M}-\mathrm{H}]^{-}$} & 359.0923 & 17.37 & 218.0 & {$[\mathrm{M}+\mathrm{H}]^{+}$} & 455.1481 & 4 & 99.7 & - & $\mathrm{C} 28 \mathrm{H} 22 \mathrm{O} 6$ \\
\hline (h) & 15.05 & 471.0907 & 4 & 100 & 202.1 & {$[\mathrm{M}-\mathrm{H}]^{-}$} & - & 15.06 & 208.1 & {$[\mathrm{M}+\mathrm{H}]^{+}$} & 473.1060 & 4 & 100 & - & C23H20 011 \\
\hline (i) & 12.86 & 491.1189 & 4 & 82.7 & 226.5 & {$[\mathrm{M}-2 \mathrm{H}]^{-}$} & $\begin{array}{l}{\left[\mathrm{M}-2 \mathrm{H}+\mathrm{H}_{2} \mathrm{O}\right]^{-}} \\
{[\mathrm{M}-2 \mathrm{H}-\text { glc }]^{-}}\end{array}$ & 12.87 & 215.2 & {$[\mathrm{M}]^{+}$} & 493.1342 & 4 & 100 & {$[\mathrm{M}+\mathrm{H}$-glc $]+$} & $\begin{array}{l}\text { malvidin- } \\
\text { 3-glucoside }\end{array}$ \\
\hline
\end{tabular}
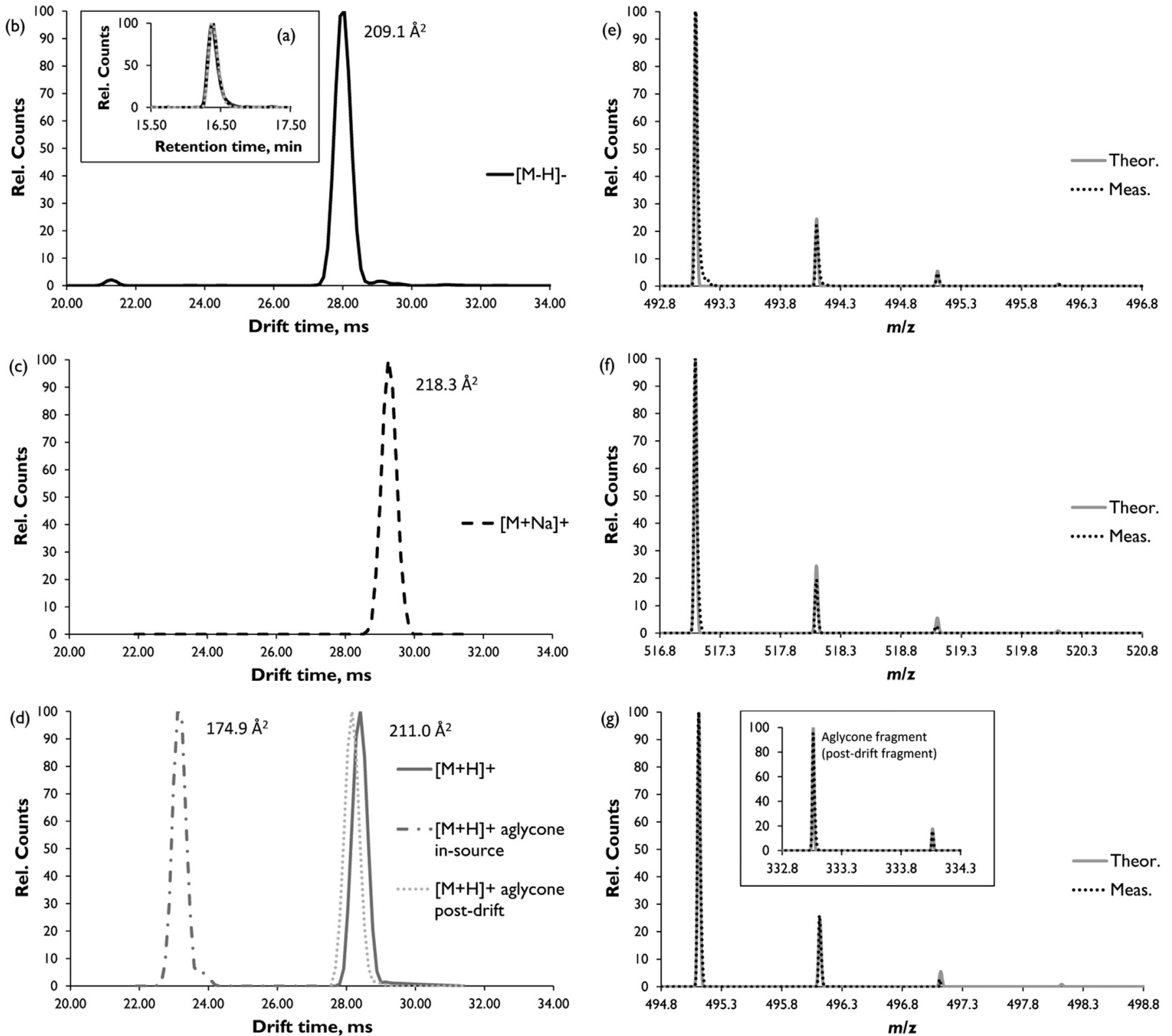

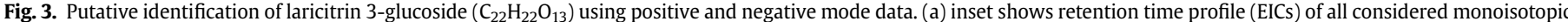

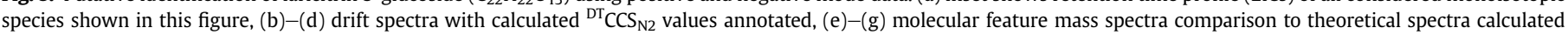
using the online EnivPat tool [38]. 
assessments (Supporting Information Figure S4). Using this approach, lists of putative compounds appearing with statistical significance in Vranec or Pinot Noir, or with substantially higher abundance than all other varieties (maintaining group frequency $\geq 75 \%$ ) could be generated and are provided as preliminary fingerprints for the wines in this study (see data in Supporting Information). It is noted at this point that some limitations arise in the interpretation of fingerprints due to practical difficulties in covering all varieties and regions adequately in such a study. Moreover, the influence of year-to-year variations also can play a significant role in wine fingerprinting, which could not be assessed for this cohort of samples. Taken together, the data from this study represent a unique and robust estimate of the fingerprints for varieties assessed in this study, but larger statistical interpretations must be considerate of these issues.

\subsection{Combining positive and negative mode data}

A number of phenolic metabolites could also be aligned (fused) across the positive and negative ionization mode datasets, providing confirmation of the correct assignment of the neutral mass. Reconciling positive and negative mode data for phenolic compounds is particularly valuable in non-targeted strategies as the combination of retention time and neutral mass alignment can be used to recover ${ }^{\mathrm{DT}} \mathrm{CCS}_{\mathrm{N} 2}$ values for corresponding protonated and sodiated species by calculating the neutral mass from the negative mode measurements. To this end, the consensus retention time and accurate mass data (i.e. $[\mathrm{M}-\mathrm{H}]^{-}$of the monoisotopic mass) for the high abundance molecular features present were exported to a compound spectral libraries containing the accurate neutral masses and retention times. The corresponding positive ionization data files were then searched against this database and matches interrogated to support the assignment by retention time and neutral mass alignment $\left(\mathrm{M}^{+},[\mathrm{M}+\mathrm{H}]^{+}\right.$and $[\mathrm{M}+\mathrm{Na}]^{+}$species allowed). Results from the fusion of the most characteristic molecular features in Vranec and Pinot Noir varieties from this study detailed in Table 2 and Table 3. A detailed example of this annotation process is shown in Fig. 3. Using data from two measurements of the same sample, up to seven identification points could be established for a molecular feature (i.e. retention time, accurate mass spectrum in both modes, CCS values for up to 3 primary ion species, and manually drift-aligned fragment ions). Although it is not possible to use CCS (or drift time) as an additional alignment parameter between ionization modes, preliminary screening of the cross-ionization mode alignment could be performed by examining the CCS values determined for the respective ion species. Some aligned molecular features were found to exhibit a large discrepancy in CCS values between the two modes, which was found in some cases to indicate mis-alignment with a post-drift fragment or in-source fragment. Thus, for effective screening of results, data from measurement of analytical standards are valuable in estimating the likelihood of a correct match for a given molecular class (Fig. 4). Following manual quality checking of these molecular features, the correlation between abundance across the two ionization modes was found to be very good in many examples with correlation coefficients $\left(R^{2}\right)$ values of $0.63-0.97$ for eleven putative metabolites in Vranec wines, and $0.70-0.99$ for nine putative metabolites in Pinot Noir providing a further endorsement of the approach for elucidation of metabolites of interest (See Supporting Information Figures S6 \& S7). Anthocyanins are of particular interest in this workflow as the cross-sample alignment should consider $\mathrm{M}^{+},[\mathrm{M}-2 \mathrm{H}]^{-}$and the proposed [37] [M-2H $\left.+\mathrm{H}_{2} \mathrm{O}\right]^{-}$ species as characteristic across the two datasets [37], as observed for the putatively identified peonidin 3-glucoside in Vranec and malvidin 3-glucoside in Merlot (Fig. 5). Of interest in such examples is the similarity in gas phase mobility behavior of the ions whereby the adducted species appears with a bimodal arrival time distribution. We therefore expect that enabling data processing workflows to search for and correctly annotate such examples based on improving understanding of such phenomena will be of substantial benefit for metabolomics-based fingerprinting of wine and similar phenol-rich samples.

\section{Conclusion}

Assessment of a range of traditionally produced wines originating from the Republic of Macedonia allowed detailed fingerprints for individual varieties to be established. Importantly, each putative compound of interest for a given wine type by statistical assessment is annotated with retention (LC), accurate mass and

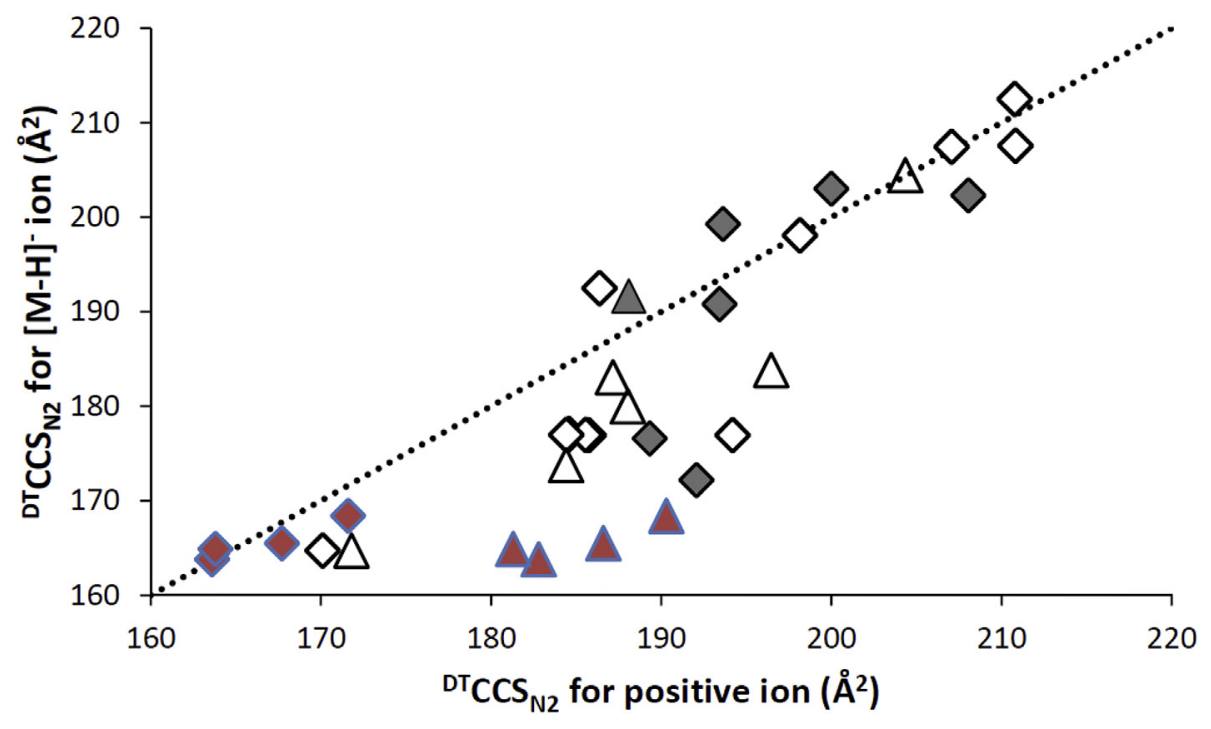

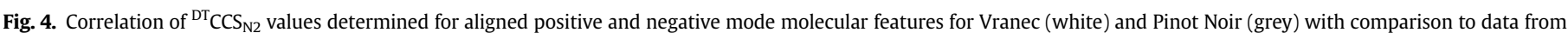

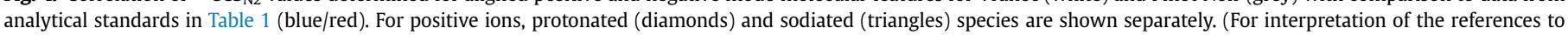
colour in this figure legend, the reader is referred to the Web version of this article.) 

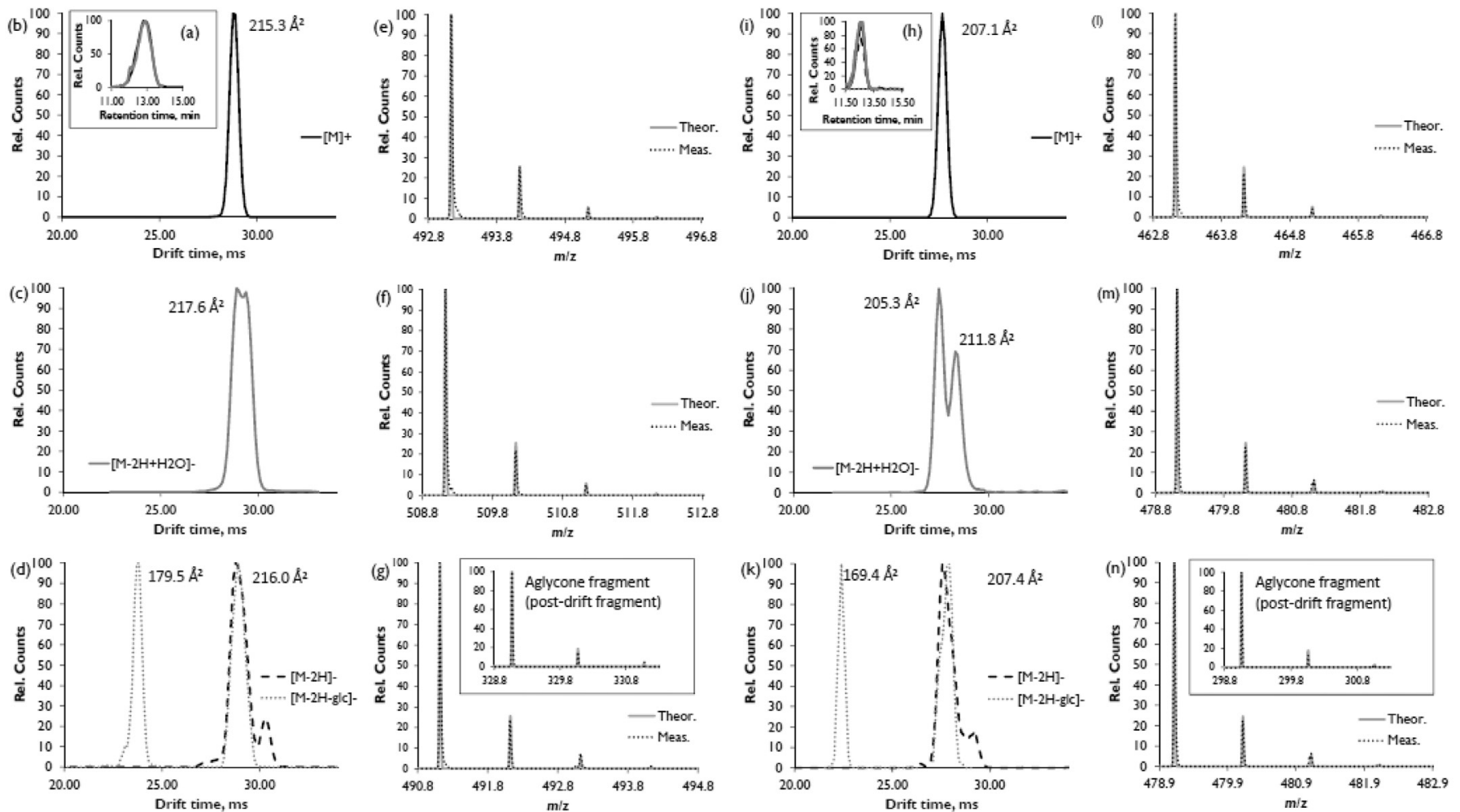

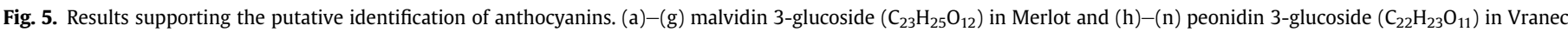
using positive and negative data. Theoretical mass spectra calculated using the online EnivPat tool [38].

standardized CCS information, all of which can be used to support future comparative studies focusing on wine metabolomics. We emphasize that the process of populating metabolite spectral libraries with CCS for pseudo-molecular ions in both ionization modes to support accurate mass information requires thorough reporting of calibration and measurement conditions in order to be considered as a useful identification point alongside retention time, accurate mass and diagnostic fragment ions. Furthermore, there is a rich amount of data from mobility-separated fragments and adducts that will require software developments to make full use of this. In this regard, the use of a method for traceable determination of ${ }^{\mathrm{DT}} \mathrm{CCS}_{\mathrm{N} 2}$ values is of particular importance in endorsing the use of nested IM separation for characterization of wine and metabolomics in general. In addition to expanding our focus toward extending higher-level metabolite identity confirmation via accurate mass/CCS database building and datamining, future work will also focus on assessing the quantitative capabilities of LC $\times$ IMQTOFMS for metabolomics, which is a significant topic of interest for non-targeted studies in general.

\section{Acknowledgements}

Vienna Business Agency and EQ BOKU VIBT GmbH are acknowledged for providing mass spectrometry instrumentation. The Austrian Agency for International Cooperation in Education and Research and Ministry of Education and Science of the Republic of Macedonia are thanked for financial support (Bilateral Project between Austria and R. Macedonia, MK 12/2016). We thank Hedda Drexler (BOKU Vienna) for support with sample preparation and measurements.

\section{Appendix A. Supplementary data}

Supplementary data to this article can be found online at https://doi.org/10.1016/j.aca.2018.11.040.

\section{References}

[1] M.E. Alañón, M.S. Pérez-Coello, M.L. Marina, Wine science in the metabolomics era, TrAC Trends Anal. Chem. (Reference Ed.) 74 (2015) 1-20, https:/ doi.org/10.1016/j.trac.2015.05.006.

[2] D. Cozzolino, Metabolomics in grape and wine: definition, current status and future prospects, Food Anal. Methods. 9 (2016) 2986-2997, https://doi.org/ 10.1007/s12161-016-0502-x.

[3] A. de Villiers, P. Alberts, A.G.J. Tredoux, H.H. Nieuwoudt, Analytical techniques for wine analysis: an African perspective; a review, Anal. Chim. Acta 730 (2012) 2-23, https://doi.org/10.1016/j.aca.2011.11.064.

[4] A. de Villiers, P. Venter, H. Pasch, Recent advances and trends in the liquidchromatography-mass spectrometry analysis of flavonoids, J. Chromatogr. A 1430 (2016) 16-78, https://doi.org/10.1016/j.chroma.2015.11.077.

[5] M.-J. Motilva, A. Serra, A. Macià, Analysis of food polyphenols by ultra highperformance liquid chromatography coupled to mass spectrometry: an overview, J. Chromatogr. A 1292 (2013) 66-82, https://doi.org/10.1016/ j.chroma.2013.01.012.

[6] M. Gleichenhagen, A. Schieber, Current challenges in polyphenol analytical chemistry, Curr. Opin. Food Sci. 7 (2016) 43-49, https://doi.org/10.1016/ j.cofs.2015.10.004.

[7] V. Vukics, A. Guttman, Structural characterization of flavonoid glycosides by multi-stage mass spectrometry, Mass Spectrom. Rev. 29 (2010) 1-16, https:// doi.org/10.1002/mas.20212.

[8] M. Arbulu, M.C. Sampedro, A. Gómez-Caballero, M.A. Goicolea, RJ. Barrio, Untargeted metabolomic analysis using liquid chromatography quadrupole time-of-flight mass spectrometry for non-volatile profiling of wines, Anal Chim. Acta 858 (2015) 32-41, https://doi.org/10.1016/j.aca.2014.12.028.

[9] C. Roullier-Gall, D. Hemmler, M. Gonsior, Y. Li, M. Nikolantonaki, A. Aron, C. Coelho, R.D. Gougeon, P. Schmitt-Kopplin, Sulfites and the wine metabolome, Food Chem. 237 (2017) 106-113, https://doi.org/10.1016 j.foodchem.2017.05.039.

[10] C. Roullier-Gall, M. Witting, D. Tziotis, A. Ruf, R.D. Gougeon, P. Schmitt-Kopplin, Integrating analytical resolutions in non-targeted wine metabolomics, Tetrahedron 71 (2015) 2983-2990, https://doi.org/10.1016/j.tet.2015.02.054. 
[11] C. Roullier-Gall, M. Witting, R.D. Gougeon, P. Schmitt-Kopplin, High precision mass measurements for wine metabolomics, Front. Chem. 2 (2014), https:// doi.org/10.3389/fchem.2014.00102.

[12] M. Zhang, J. Sun, P. Chen, FlavonQ: an automated data processing tool for profiling flavone and flavonol glycosides with ultra-high-performance liquid chromatography-diode array detection-high resolution accurate mass-mass spectrometry, Anal. Chem. 87 (2015) 9974-9981, https://doi.org/10.1021/ acs.analchem.5b02624.

[13] K.M. Kalili, J. Vestner, M.A. Stander, A. de Villiers, Toward unraveling grape tannin composition: application of online hydrophilic interaction chromatography $\times$ reversed-phase liquid chromatography-time-of-flight mass spectrometry for grape seed analysis, Anal. Chem. 85 (2013) 9107-9115, https://doi.org/10.1021/ac401896r.

[14] C.M. Willemse, M.A. Stander, J. Vestner, A.G.J. Tredoux, A. de Villiers, Comprehensive two-dimensional hydrophilic interaction chromatography (HILIC) $\times$ reversed-phase liquid chromatography coupled to high-resolution mass spectrometry (RP-LC-UV-MS) analysis of anthocyanins and derived pigments in red wine, Anal. Chem. 87 (2015) 12006-12015, https://doi.org/ 10.1021/acs.analchem.5b03615.

[15] C.M. Ajila, S.K. Brar, M. Verma, R.D. Tyagi, S. Godbout, J.R. Valéro, Extraction and analysis of polyphenols: recent trends, Crit. Rev. Biotechnol. 31 (2011) 227-249, https://doi.org/10.3109/07388551.2010.513677.

[16] R. Díaz, H. Gallart-Ayala, J.V. Sancho, O. Nuñez, T. Zamora, C.P.B. Martins, F. Hernández, S. Hernández-Cassou, J. Saurina, A. Checa, Told through the wine: a liquid chromatography-mass spectrometry interplatform comparison reveals the influence of the global approach on the final annotated metabolites in non-targeted metabolomics, J. Chromatogr. A 1433 (2016) 90-97. https://doi.org/10.1016/j.chroma.2016.01.010.

[17] K. Ortmayr, T.J. Causon, S. Hann, G. Koellensperger, Increasing selectivity and coverage in LC-MS based metabolome analysis, TrAC Trends Anal. Chem. (Reference Ed.) $82 \quad$ (2016) 358-366, https://doi.org/10.1016/ j.trac.2016.06.011.

[18] J.C. May, C.R. Goodwin, J.A. McLean, Ion mobility-mass spectrometry strategies for untargeted systems, synthetic, and chemical biology, Curr. Opin. Biotechnol. 31 (2015) 117-121, https://doi.org/10.1016/j.copbio.2014.10.012.

[19] X. Zheng, R. Wojcik, X. Zhang, Y.M. Ibrahim, K.E. Burnum-Johnson, D.J. Orton, M.E. Monroe, R.J. Moore, R.D. Smith, E.S. Baker, Coupling front-end separations, ion mobility spectrometry, and mass spectrometry for enhanced multidimensional biological and environmental analyses, Annu. Rev. Anal. Chem. 10 (2017) 71-92, https://doi.org/10.1146/annurev-anchem-061516045212.

[20] V. D'Atri, T. Causon, O. Hernandez-Alba, A. Mutabazi, J.-L. Veuthey, S. Cianferani, D. Guillarme, Adding a new separation dimension to MS and LC-MS: what is the utility of ion mobility spectrometry? J. Separ. Sci. 41 (2018) 20-67, https://doi.org/10.1002/jssc.201700919.

[21] X. Zheng, N.A. Aly, Y. Zhou, K.T. Dupuis, A. Bilbao, V.L. Paurus, D.J. Orton, R. Wilson, S.H. Payne, R.D. Smith, E.S. Baker, A structural examination and collision cross section database for over 500 metabolites and xenobiotics using drift tube ion mobility spectrometry, Chem. Sci. 8 (2017) 7724-7736, https://doi.org/10.1039/C7SC03464D.

[22] T. Mairinger, T.J. Causon, S. Hann, The potential of ion mobility-mass spectrometry for non-targeted metabolomics, Curr. Opin. Chem. Biol. 42 (2018) 9-15, https://doi.org/10.1016/j.cbpa.2017.10.015.

[23] G. Paglia, J.P. Williams, L. Menikarachchi, J.W. Thompson, R. Tyldesley-Worster, S. Halldórsson, O. Rolfsson, A. Moseley, D. Grant, J. Langridge, B.O. Palsson, G. Astarita, Ion mobility derived collision cross sections to support metabolomics applications, Anal. Chem. 86 (2014) 3985-3993, https:// doi.org/10.1021/ac500405x.

[24] S.M. Stow, T.J. Causon, X. Zheng, R.T. Kurulugama, T. Mairinger, J.C. May, E.E. Rennie, E.S. Baker, R.D. Smith, J.A. McLean, S. Hann, J.C. Fjeldsted, An interlaboratory evaluation of drift tube ion mobility-mass spectrometry collision cross section measurements, Anal. Chem. 89 (2017) 9048-9055, https://doi.org/10.1021/acs.analchem.7b01729.

[25] E.A. Mason, H.W. Schamp, Mobility of gaseous lons in weak electric fields, Ann. Phys. 4 (1958) 233-270, https://doi.org/10.1016/0003-4916(58)900496.

[26] L. Jaitz, K. Siegl, R. Eder, G. Rak, L. Abranko, G. Koellensperger, S. Hann, LC-MS/ MS analysis of phenols for classification of red wine according to geographic origin, grape variety and vintage, Food Chem. 122 (2010) 366-372, https:// doi.org/10.1016/j.foodchem.2010.02.053.

[27] T.J. Causon, M. Došen, G. Reznicek, S. Hann, Workflow development for the analysis of phenolic compounds in wine using liquid chromatography combined with drift-tube ion mobility-mass spectrometry, LC-GC N. Am. 34 (2016) 854-867. http://www.chromatographyonline.com/workflowdevelopment-analysis-phenolic-compounds-wine-using-liquidchromatography-combined-drift-tub.

[28] PNNL PreProcessor | Integrative Omics. https://omics.pnl.gov/software/pnnlpreprocessor (accessed February 28, 2018)

[29] A. Bilbao, B.C. Gibbons, G.W. Slysz, K.L. Crowell, M.E. Monroe, Y.M. Ibrahim, R.D. Smith, S.H. Payne, E.S. Baker, An algorithm to correct saturated mass spectrometry ion abundances for enhanced quantitation and mass accuracy in omic studies, Int. J. Mass Spectrom. (2017), https://doi.org/10.1016/ j.ijms.2017.11.003.

[30] X. Zhang, K. Kew, R. Reisdorph, M. Sartain, R. Powell, M. Armstrong, K. Quinn, C. Cruickshank-Quinn, S. Walmsley, S. Bokatzian, E. Darland, M. Rain, K. Imatani, N. Reisdorph, Performance of a high-pressure liquid chromatography-ion mobility-mass spectrometry system for metabolic profiling, Anal. Chem. 89 (2017) 6384-6391, https://doi.org/10.1021/ acs.analchem.6b04628.

[31] V.L. Singleton, M. Salgues, J. Zaya, E. Trousdale, Caftaric acid disappearance and conversion to products of enzymic oxidation in grape must and wine, Am. J. Enol. Vitic. 36 (1985) 50-56 (accessed April 11, 2018), http://www. ajevonline.org/content/36/1/50.

[32] V.F. Cheynier, E.K. Trousdale, V.L. Singleton, M.J. Salgues, R. Wylde, Characterization of 2-S-glutathionyl caftaric acid and its hydrolysis in relation to grape wines, J. Agric. Food Chem. 34 (1986) 217-221, https://doi.org/10.1021/ jf00068a016.

[33] V. Ivanova, Á. Dörnyei, L. Márk, B. Vojnoski, T. Stafilov, M. Stefova, F. Kilár Polyphenolic content of Vranec wines produced by different vinification conditions, Food Chem. 124 (2011) 316-325, https://doi.org/10.1016/ j.foodchem.2010.06.039.

[34] V. Ivanova, M. Stefova, B. Vojnoski, Á. Dörnyei, L. Márk, V. Dimovska, T. Stafilov, F. Kilár, Identification of polyphenolic compounds in red and white grape varieties grown in R. Macedonia and changes of their content during ripening, Food Res. Int. 44 (2011) 2851-2860, https://doi.org/10.1016/ j.foodres.2011.06.046.

[35] V. Ivanova-Petropulos, I. Hermosín-Gutiérrez, B. Boros, M. Stefova, T. Stafilov, B. Vojnoski, Á. Dörnyei, F. Kilár, Phenolic compounds and antioxidant activity of Macedonian red wines, J. Food Compos. Anal. 41 (2015) 1-14, https:// doi.org/10.1016/j.jfca.2015.01.002.

[36] S. Stephan, J. Hippler, T. Köhler, A.A. Deeb, T.C. Schmidt, O.J. Schmitz, Contaminant screening of wastewater with HPLC-IM-qTOF-MS and LC+LCIM-qTOF-MS using a CCS database, Anal. Bioanal. Chem. 408 (2016) 6545-6555, https://doi.org/10.1007/s00216-016-9820-5.

[37] J. Sun, L. Lin, P. Chen, Study of the mass spectrometric behaviors of anthocyanins in negative ionization mode and its applications for characterization of anthocyanins and non-anthocyanin polyphenols, Rapid Commun. Mass Spectrom. 26 (2012) 1123-1133, https://doi.org/10.1002/rcm.6209.

[38] M. Loos, C. Gerber, F. Corona, J. Hollender, H. Singer, Accelerated isotope fine structure calculation using pruned transition trees, Anal. Chem. 87 (2015) 5738-5744, https://doi.org/10.1021/acs.analchem.5b00941. 